\title{
VIABILIZAÇÃO DE REJEITOS DE VIDRO PARA PRODUÇÃO DE TIJOLOS CERÂMICOS
}

\author{
Á. C. P. Galvão ${ }^{1}$, A. C. M. Farias e L. G. M. Souza \\ Universidade Federal do Rio Grande do Norte \\ E-mail: galvao_alvaro@hotmail.com ${ }^{1}$
}

Artigo submetido em julho/2013 e aceito em agosto/2013

\section{RESUMO}

Atualmente são consumidos grandes quantidades de materiais para a construção de moradias populares. Baseado nesta situação, este trabalho se dedica na produção de blocos cerâmicos com o rejeito de vidro moído (resultante da lapidação em vidrarias). O pó de vidro foi avaliado por Granulometria a laser, Fluorescência e Difração de Raios X. Foram feitos corpos-de-prova cilíndricos compostos por cimento, areia, gesso, cal e vidro moído. O resíduo de vidro passou por processo de peneiramento, obtendo-se um pó mais fino $(160 \mu \mathrm{m})$, facilitando a mistura entre os elementos constituintes do bloco cerâmico, ou compósito. Uma utilização prática do compósito seria a produção de um bloco construtivo mais leve, com maior resistência térmica e mais barato que os fabricados por materiais convencionais. A partir da caracterização destes blocos cerâmicos, obtidos com o rejeito de vidro, foi possível identificar as condições de conforto térmico e de resistência mecânica. É importante considerar que a utilização do pó de vidro na fabricação de blocos implica na redução do rejeito do vidro lapidado, o qual provavelmente seria descartado no meio ambiente.

PALAVRAS-CHAVE: compósito, baixo custo, conforto térmico, aproveitamento de resíduos, casas populares.

\section{VIABILITY OF WASTES GLASS FOR THE PRODUCTION OF CERAMIC BRICKS}

\section{ABSTRACT}

Currently are consumed large quantities of materials for the construction of popular housing. Based on this situation, the work aims to produce ceramic blocks with the reject of crushed glass (resulting from the stoning in glassware). The glass powder was evaluated by laser granulometry, X-Ray Fluorescence and X-Ray Diffraction. The cylindrical specimens composed by cement, sand, gypsum, lime and ground waste glass were made. The glass waste underwent by sieving process, obtaining a glass powder thinner $(160 \mu \mathrm{m})$, which provided a better mixing between the constituent elements of the composite. A practical use of the composite would be the production of lightest constructive block with greater thermal resistance and cheaper than those produced by conventional materials. From the characterization of these ceramic blocks obtained with the glass waste was achieved to identify the thermal comfort conditions and mechanical resistance. It is important to consider that the use of powder glass in the manufacture of blocks implies the reduction of glass waste, which probably would have been discarded in the environment.

KEYWORDS: composite, low cost, thermal comfort, waste recovery, housing. 


\section{VIABILIZAÇÃO DE REJEITOS DE VIDRO PARA PRODUÇÃO DE TIJOLOS CERÂMICOS}

\section{INTRODUÇÃO}

A reciclagem de resíduos, assim como qualquer atividade humana, também pode causar impactos ao meio ambiente. Variáveis como o tipo de resíduo, a tecnologia empregada e a utilização proposta para o material reciclado podem tornar o processo de reciclagem ainda mais impactante do que o próprio resíduo; o que era antes de ser reciclado. Dessa forma, o processo de reciclagem acarreta riscos ambientais que precisam ser adequadamente gerenciados (Ângulo et al., 2001).

Lima et al. (2011) utilizou as técnicas de granulometria a laser, fluorescência de raios-X e difração de raios-X para caracterizar amostras de pó de vidro provenientes de monitores de computadores. Sua proposta de reciclagem do vidro foi sugerida por se tratar de um material que apresentava grande quantidade de óxido de silício, composto essencial para a formação da rede vítrea, cujo objetivo era diminuir a quantidade destes resíduos depositados no meio ambiente.

O vidro é o material que possui a mais elevada estabilidade química e pode se ligar quimicamente com qualquer elemento da tabela periódica; uma vez que seus resíduos geralmente possuem uma composição química bastante complexa. Além disso, o processo de vitrificação geralmente reduz o volume do resíduo de vidro, podendo ser armazenado por longos prazos (Scarinci et al., 2000).

Luz e Ribeiro (2008) substituíram o feldspato sódico por resíduo de vidro devido à similaridade e por apresentar, quando incorporado em misturas cerâmicas, um bom potencial como novo fundente, tornando possível a obtenção de uma fase vítrea durante a queima do grês porcelanato. Além de acelerar o processo de densificação durante a queima, o pó de vidro não é uma opção mais indicada para a substituição total do feldspato, pois pode gerar um produto nãoconforme. No entanto sua substituição parcial pode proporcionar uma grande contribuição econômica e ecológica pelo uso do pó de vidro, resíduo industrial inerte; que, ao ser descartado, pode ser conduzido aos rios, aumentando o $\mathrm{pH}$ e a turbidez das águas.

Santos (2009) defendeu a viabilidade do uso de sucatas de vidro na produção de novos materiais compósitos e concluiu, no seu trabalho sobre sinterização de PV (pó de vidro), que conforme o tamanho médio da partícula era reduzido $(98,6 \mu \mathrm{m} ; 30,7 \mu \mathrm{m} ; 14,9 \mu \mathrm{m})$, maior era a sua reatividade química devido ao aumento da energia superficial. A partir dessa análise, ele observou que a temperatura inicial de retração durante o processo de sinterização era diretamente proporcional ao tamanho desses pós. Consequentemente, haveria a diminuição do consumo de energia e impacto ambiental causado pela geração de gases.

Coutinho (2011) utilizou cacos de vidro descartados pelas indústrias vidreiras, cujo principal objetivo era a substituição do cimento Portland (CLT) por resíduo de vidro na fabricação de argamassa. Este resíduo foi processado em laboratório por esmagamento e moído, obtendose o pó de vidro. Confeccionou-se quatro tipos de argamassas com composições equivalentes: (1) $100 \%$ de cimento Portland (CLT); (2) $90 \%$ de cimento e $10 \%$ de pó de vidro (PV10); (3) $80 \%$ de cimento e $20 \%$ de pó de vidro (PV 20); (4) $90 \%$ de cimento e $10 \%$ de sílica de fumo comercial (SF). Verificou-se que a resistência da mistura aumentava com a substituição deste cimento por pó de vidro, sendo viável econômico e ambientalmente. 
A reutilização do pó de vidro no processo produtivo acarreta numa vantajosa diminuição da energia necessária para sua fundição, pois os resíduos de vidro podem ser reciclados como agregado para cimento Portland e concreto asfáltico, com a economia de agregados naturais comumente utilizados para este fim. Ainda, a sucata de vidro é empregada como agregados para leitos de estradas, como materiais abrasivos, blocos de pavimentação, tanques sépticos de sistemas de tratamento de esgoto, filtros, janelas, clarabóias e telhas. Nestas aplicações utiliza-se a sucata de vidro moída e/ou em cacos (cujo tamanho varia com a aplicação) adicionada em porcentagens adequadas aos elementos já constituintes (Reciclar para Construir, 2012).

Segundo o CEMPRE (2013), o Brasil produz em média 980 mil ton/ano de embalagens de vidro usando cerca de $45 \%$ de matéria-prima reciclada na forma de cacos. Parte delas foi gerada como refugo nas fábricas e outra parte retornou por meio da coleta seletiva. Apenas $47 \%$ das embalagens de vidro foram recicladas em 2010 no Brasil, somando 470 mil ton/ano. Além de voltar à produção de embalagens, a sucata pode ser aplicada na composição de asfalto e pavimentação de estradas, construção de sistemas de drenagem contra enchentes, produção de espuma e fibra de vidro, bijuterias e tintas reflexivas.

O presente trabalho trata da aplicação do pó de vidro, resultante do processo de lapidação na indústria vidreira. Este resíduo de vidro foi aplicado na fabricação de blocos cerâmicos, com fins de diminuir a poluição ambiental causada pela sua eliminação em aterros sanitários e rios, visto que este pó não pode ser reciclado. A utilização do pó de vidro na produção de blocos em maiores proporções pode trazer maior viabilidade econômica, além de ser compatível com características semelhantes ou superiores aos blocos convencionais produzidos comercialmente.

\section{MATERIAIS E MÉTODOS}

Este trabalho tratou do estudo da fabricação de três tipos de blocos cerâmicos de proporções e materiais diferenciados e com tempos de cura de 7, 14 e 28 dias, onde foi fabricado um total de 66 corpos-de-prova e sua caracterização. Os corpos-de-prova foram classificados como:

- Tipo 1 - Padrão convencional com proporção 1:3:1 (cimento, areia e cal, respectivamente);

- Tipo 2 - Padrão convencional com proporção 1:3:1:1 (cimento, areia, cal e pó de vidro, respectivamente);

- Tipo 3 - Proporção de com proporção 1:1:1 (cimento, gesso e pó de vidro, respectivamente).

O pó de vidro, originado da lapidação, foi doado pela empresa DVN Vidros LTDA, localizada em Natal/RN. Este resíduo foi caracterizado através de granulometria a laser, Florescência de Raios-X (FRX) e Difração de Raios-X (DRX).

As propriedades dos blocos foram avaliadas e comparadas através dos ensaios de resistência à compressão, absorção de água, índice de vazios e de sua viabilidade econômica. Estes ensaios foram executados nos Laboratórios de Materiais Construção Civil, de Cerâmica, de Máquinas Hidráulicas e Energia Solar da UFRN.

Foram utilizados os seguintes equipamentos para o ensaio: 
- Balança eletrônica digital OHAUS, Adventurer ${ }^{\mathrm{tm}}$ Pro, carga máxima de 8100 gramas e mínima de 5 gramas, com resolução 0,1 grama;

- Prensa Hidráulica AMSLER, Suíça, escala 10000 kg, precisão 10 kg. Capacidade de 10 a 100 toneladas, (com velocidade de carregamento contínuo de 0,20 a $0,40 \mathrm{MPa} / \mathrm{s}^{-1}$ );

- Estufa com faixa de operação $105^{\circ} \mathrm{C}$ a $110^{\circ} \mathrm{C}$.

\subsection{MATERIAIS}

O processo de fabricação dos blocos cerâmicos foi constituído de cinco etapas, descritas abaixo:

1- $\quad$ Obtenção e trituração do resíduo de vidro com o auxílio de pistilo e almofariz.

2- $\quad$ Utilização de um moinho de bolas com esferas de alumina durante cinco horas para diminuição das partículas do resíduo de vidro.

3- Após peneiramento, as partículas apresentaram granulometria entre $100 \mu \mathrm{m}$ e $300 \mu \mathrm{m}$ via granulômetro a laser.

4- Preparação dos moldes cilíndricos, com dimensões de $10 \mathrm{~cm} \times 5 \mathrm{~cm}$, para a fabricação dos corpos-de-prova;

5- Remoção dos corpos-de-prova dos moldes cilíndricos com tempo de cura de 7, 14 e 28 dias.

A Figura 1 mostra o processo de fabricação dos corpos-de-prova desde a preparação do pó de vidro, até a obtenção dos blocos cerâmicos.

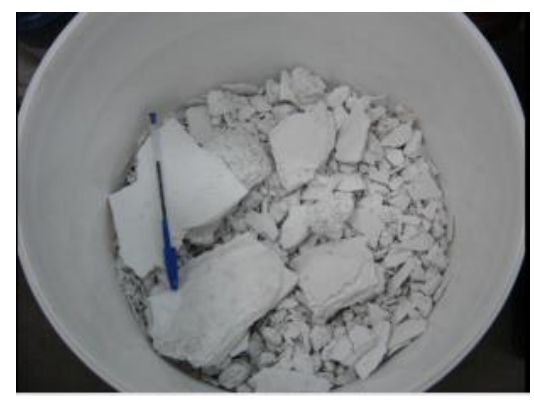

(a)

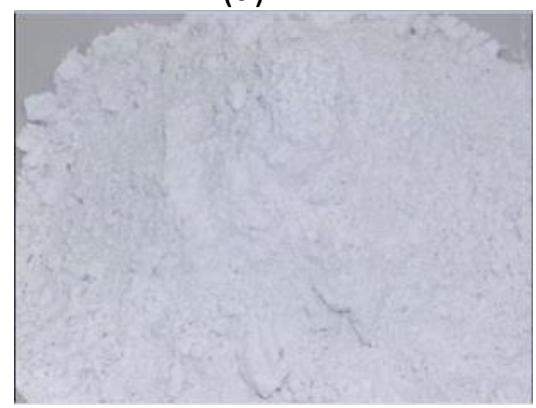

(d)

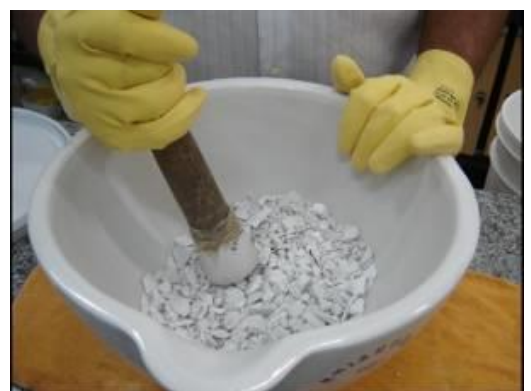

(b)

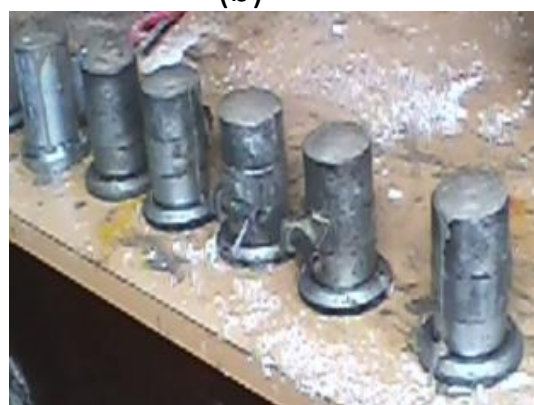

(e)

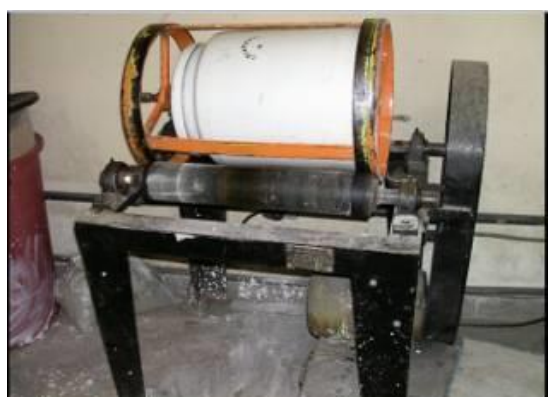

(c)

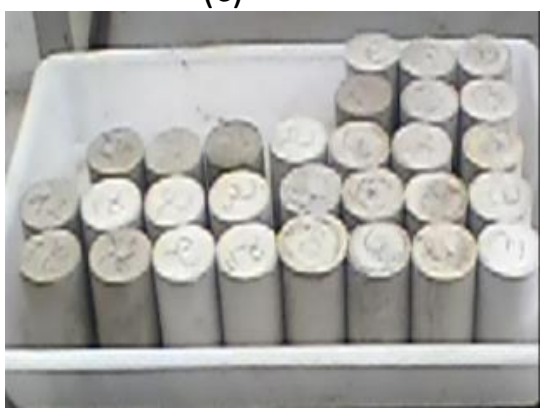

(f)

Figura 1 - Etapas do processo de fabricação dos corpos-de-prova cerâmicos: (a) e (b) etapa 1, (c) etapa 2, (d) etapa 3 , (e) etapa 4 e (f) etapa 5.

Após o processo de fabricação dos corpos-de-prova cerâmicos, deu-se início a sua caracterização por absorção de água e índice de vazios e a realização de ensaios de resistência à compressão. 


\subsection{MÉTODOS}

\subsubsection{Caracterização do Resíduo Pó de Vidro}

A caracterização do resíduo de pó de vidro proveniente da indústria de vidrarias visou proporcionar alternativas tecnológicas e ambientais para a reciclagem dos mesmos através do estudo das propriedades espectroscópicas e morfológicas deste resíduo. Sendo assim, esse material foi caracterizado por distribuição granulométrica e pelas técnicas de Fluorescência de raios-X (FRX) e Difração de raios-X (DRX).

A distribuição granulométrica foi realizada pela técnica de classificação de partículas por difração a laser. $O$ pó de vidro foi peneirado e a porção selecionada foi quantidade passante na peneira de malha 50 ABNT $(<300 \mu \mathrm{m})$. O equipamento utilizado foi um Granulômetro a laser, modelo CILAS $1180(0,04 \mu \mathrm{m}-2.500 \mu \mathrm{m})$ do Laboratório de Técnicas Mineral e de Materiais/NIT/UFRN.

A análise química do pó de vidro foi realizada por fluorescência de raios $\mathrm{X}$ pelo método do semiquantitativo, em forma de pó, sob atmosfera a vácuo, colimador $10 \mathrm{~mm}$, cujo equipamento utilizado foi o modelo XFR-1800 marca SHIMADZU pertencente ao Laboratório de NUP-ER (Núcleo de Estudos em Petróleo e Energias Renováveis) /CCET/UFRN.

A análise de difração de raios $X$ foi realizada em um equipamento difratômetro de raios $X$ da SHIMADZU, modelo XRD-7000 com radiação de CuK $\alpha$ e comprimento de onda $\lambda=1,5406 \AA$, que opera a uma voltagem de $40 \mathrm{KV}$ com $30 \mathrm{~mA}$ de corrente. A amostra em forma de pó (\#50) foi analisada em um intervalo de varredura entre 10 e 90 graus, a uma taxa de $2 \circ \mathrm{O} / \mathrm{min}$. $O$ ensaio foi realizado no Laboratório de Engenharia de Materiais/NIT/UFRN.

\subsubsection{Determinação das Massas Seca, Saturada e Imersa}

Para a determinação da massa seca, os corpos-de-prova foram colocados anteriormente em uma estufa a $100 \stackrel{\circ}{\circ} \pm 5$ ㄷ C por 12 horas, visando à eliminação total da massa de água. Após serem retirados da estufa, os corpos-de-prova foram colocados sobre uma bancada em laboratório, à temperatura ambiente, por seis horas. Em seguida, os mesmos tiveram suas massas medidas usando uma balança digital eletrônica, Fig. 2(a). A massa saturada destes corpos-de-prova foi medida após sua imersão em água, Fig. 2(b) por 24 horas à temperatura ambiente; enquanto a medida da massa imersa ocorreu numa balança hidrostática com o corpode-prova imerso em água, Fig. 2(c).
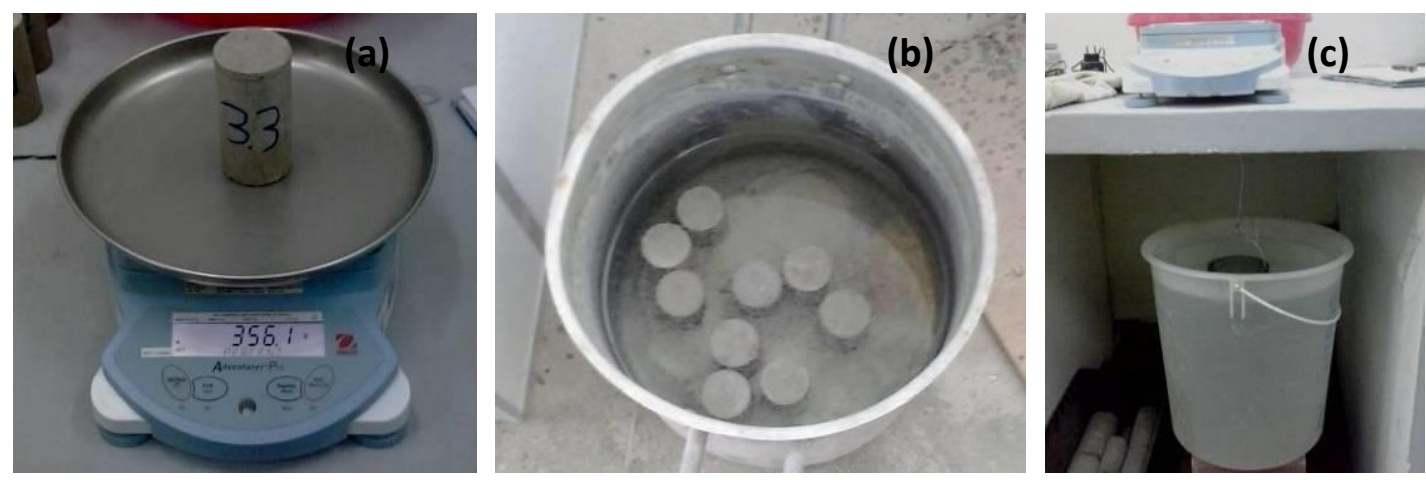

Figura 2 - Medições de massa a) seca, b) saturada e c) imersa de blocos cerâmicos. 


\subsubsection{Determinação dos Índices de Absorção de Água e de Vazios}

A determinação do índice de absorção foi realizada pela análise do percentual de água absorvida nos corpos-de-prova, conforme equação 1.

$$
A A=\frac{M u-M s}{M s} x 100 \%
$$

onde:

$\mathbf{A A}=$ índice de absorção de água; $\mathbf{M} \boldsymbol{u}=$ massa saturada e $\mathbf{M s}=$ massa seca.

A determinação do índice de vazios consiste da pesagem dos corpos-de-prova a seco, saturados e imersos em água para análise de sua porosidade. Este índice foi calculado através da equação 2.

$$
I V=\frac{M u-M s}{M u-M i} x 100 \%
$$

equação (2)

onde:

$\boldsymbol{I V}=$ índice de vazios; $\boldsymbol{M i}=$ massa imersa.

\subsubsection{Ensaio de Resistência à Compressão}

O ensaio de resistência à compressão é útil para estimar a máxima resistência do corpode-prova durante a aplicação de uma força axial compressiva. Ele precede de algumas preparações, como por exemplo, o capeamento dos corpos-de-prova à base de enxofre em suas faces, cujo objetivo é melhorar o nivelamento do corpo-de-prova na máquina de ensaio. Logo em seguida é necessário configurar o nível de carga e altura inicial de compressão. A Figura 3 apresenta estas etapas e a execução do ensaio de resistência à compressão.
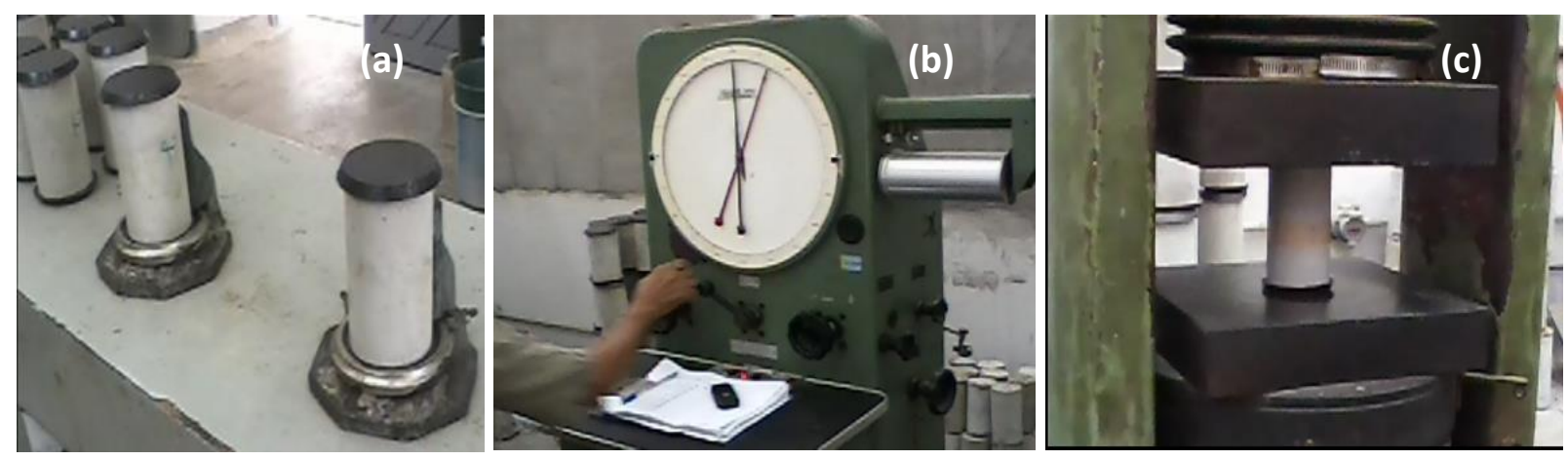

Figura 3 - Etapas do ensaio de compressão: (a) capeamento, (b) configuração e (c) compressão em andamento.

\section{RESULTADOS E DISCUSSÃO}

\subsection{Caracterização do Resíduo Pó de Vidro}

\subsubsection{Distribuição de Tamanho de Partícula}


A Figura 4 apresenta um histograma gerado da distribuição das partículas, no qual foi obtido um diâmetro médio de $161 \mu \mathrm{m}$, cujos tamanhos médios para 10, 50 e $90 \%$ (valores cumulativos) foram $7 \mu \mathrm{m}, 153 \mu \mathrm{m}$ e $320 \mu \mathrm{m}$, respectivamente.

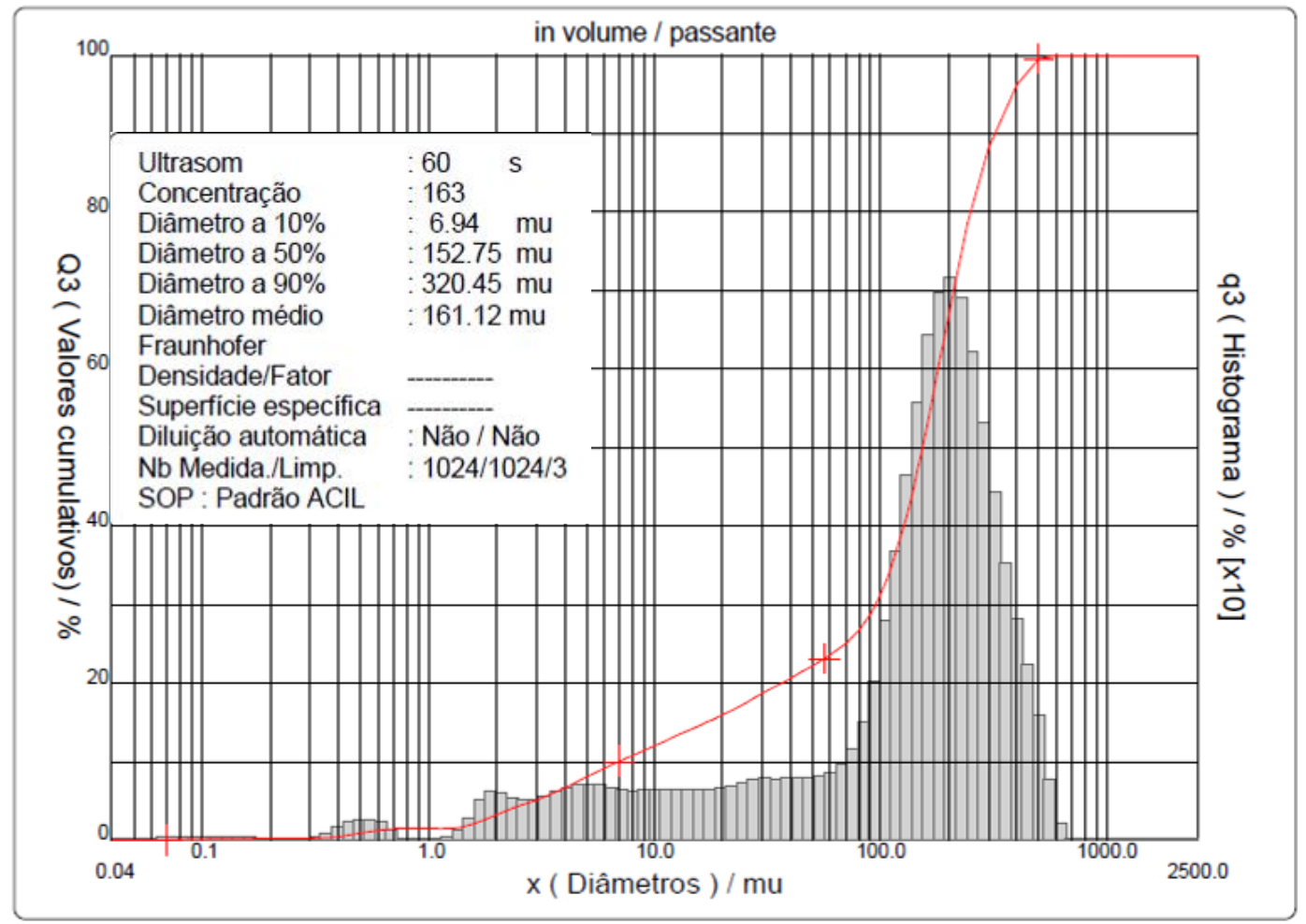

Figura 4 - Histograma da distribuição granulométrica do pó de vidro.

\subsubsection{Fluorescência de Raios-X}

$\mathrm{Na}$ análise de Fluorescência de raios $\mathrm{X}$ foram identificadas as composições químicas em porcentagem (\%) de óxidos presentes no pó de vidro proveniente do resíduo da lapidação de vidro, conforme apresentado na Tab. 1.

Tabela 1: Composição química do pó de vidro (óxidos, \%) obtida por fluorescência de raios $\mathrm{X}$

\begin{tabular}{|c|c|}
\hline Óxidos & Percentual (\%) \\
\hline $\mathrm{SiO}_{2}$ & 59,245 \\
\hline $\mathrm{CaO}$ & 20,436 \\
\hline $\mathrm{Na}_{2} \mathrm{O}$ & 10,712 \\
\hline $\mathrm{MgO}$ & 3,969 \\
\hline $\mathrm{ZrO}_{2}$ & 3,411 \\
\hline $\mathrm{Al}_{2} \mathrm{O}_{3}$ & 1,156 \\
\hline $\mathrm{K}_{2} \mathrm{O}$ & 0,551 \\
\hline $\mathrm{Fe}_{2} \mathrm{O}_{3}$ & 0,212 \\
\hline $\mathrm{SO}_{2}$ & 0,203 \\
\hline $\mathrm{IO}_{3}$ & 0,057 \\
\hline $\mathrm{TiO}_{2}$ & 0,024 \\
\hline $\mathrm{SnO}_{2}$ & 0,019 \\
\hline $\mathrm{P}_{2} \mathrm{O}_{5}$ & 0,006 \\
\hline
\end{tabular}


Pode-se observar que o pó de vidro analisado apresenta composição química predominantemente de óxido de silício $\left(\mathrm{SiO}_{2}\right)$, cujo percentual foi de $59,245 \%$. O óxido de silício é o responsável por formar a rede vítrea. O óxido de cálcio $(\mathrm{CaO})$ é principal responsável pela coloração branca e proporciona estabilidade ao vidro contra ataques de agentes atmosféricos. A resistência mecânica do vidro é aumentada em função da presença dos óxidos de alumínio $\left(\mathrm{Al}_{2} \mathrm{O}_{3}\right)$, de zircônio $\left(\mathrm{ZrO}_{2}\right)$ e de magnésio $(\mathrm{MgO})$; este último garante maior resistência ao vidro para suportar mudanças bruscas de temperatura. Os óxidos dos metais alcalinos e metais alcalinos terrosos (óxidos de sódio, cálcio, e potássio) presentes funcionam como modificadores de rede, sendo responsáveis por romper a estrutura vítrea, diminuindo assim a viscosidade do vidro.

\subsubsection{Difração de Raios-X}

A Figura 5 apresenta o difratograma do pó de vidro oriundo do processo de lapidação executado na indústria vidreira.

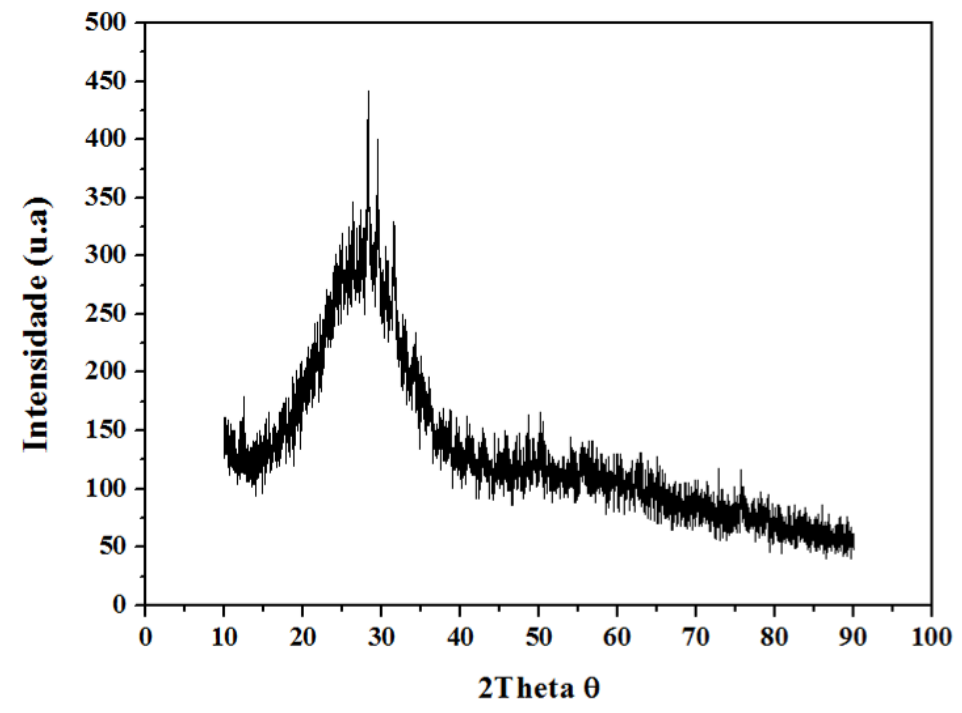

Figura 5 - Difratograma de raios-X do pó de vidro.

Através da curva difratométrica do pó de vidro proveniente do resíduo da lapidação do vidro, observou-se que os há ausência de fases cristalinas, isto é, este espectro representa uma banda típica amorfa em torno de $27^{\circ}$, proveniente da presença de sílica na amostra.

\subsection{ENSAIOS DE ÍNDICES DE VAZIOS}

A Figura 6 destaca os valores dos índices de vazios, ou porosidade, obtidos para os corposde-prova dos Tipos 1, 2 e 3 com 28 dias de cura. De acordo com estes resultados, notou-se que os corpos-de-prova Tipos 1 e 2 apresentaram características semelhantes; sendo seu índice de absorção de $\approx 28 \%$. Enquanto blocos do Tipo 3 obtiveram maiores índice de absorção ( $\approx 33 \%$ ). 


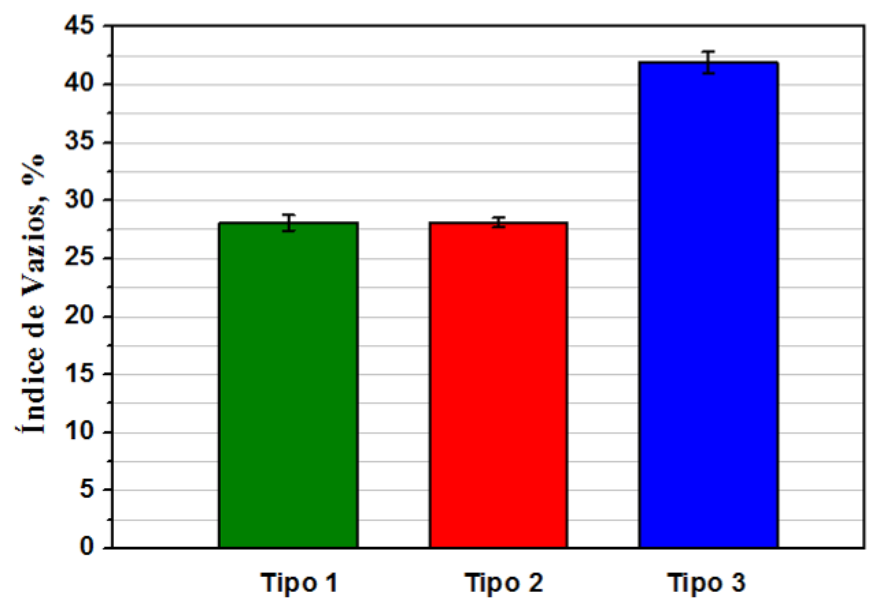

Figura 6 - Índice de vazios dos corpos-de-prova Tipos 1, 2 e 3 após 28 dias de cura.

\subsection{ENSAIO DE ABSORÇÃO DA ÁGUA}

A Figura 7 mostra o percentual de água retida por cada tipo de corpo-de-prova com 28 dias de cura durante o ensaio de absorção de água. Notou-se que os Tipos 1 e 2 apresentaram uma média de absorção de água entre $16 \%$ e 18\%, respectivamente. Esta é uma margem aceitável na fabricação de blocos. Entretanto, os corpos-de-prova do Tipo 3 apresentaram os maiores índices de absorção de água e de índice de vazios. Deste modo, deduz-se que há uma relação proporcional entre o índice de vazios e o índice de absorção de água.

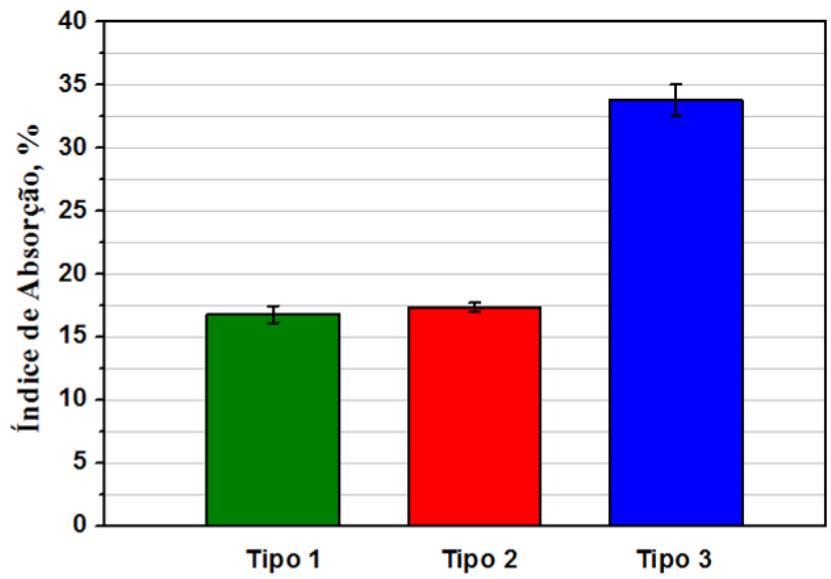

Figura 7 - Índice de absorção de água para os Tipos 1, 2 e 3 após 28 dias de cura.

\subsection{RESISTÊNCIA À COMPRESSÃO}

O gráfico da Figura 8 mostra os resultados dos ensaios de compressão em MPa, realizados após 7, 14 e 28 dias de cura, para os corpos-de-prova Tipo 1, 2 e 3.

Como observado no gráfico da Figura 8, com a adição do pó de vidro nos blocos Tipo 2 , notou-se que, para o tempo de cura de 7 dias e 14 dias, a resistência à compressão assemelha-se à do Tipo 1 . No tempo de cura de 28 dias, o Tipo 2 apresentou resistência à compressão $(6,5$ $\mathrm{MPa}$ ) superior aos Tipos 1 e 2. Disto, destaca-se a importância da adição de pó de vidro como elevador do desempenho mecânico de blocos cerâmicos. Entretanto deve-se levar em 
consideração a quantidade máxima que pode ser adicionada durante a formulação sem comprometer consideravelmente sua resistência mecânica.

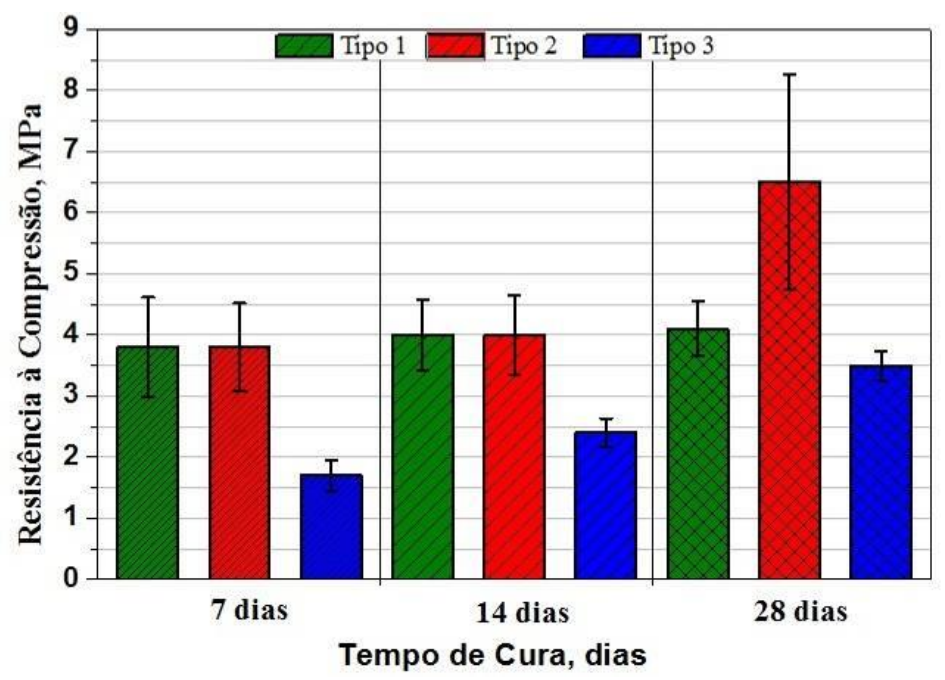

Figura 8 - Ensaios de resistência à compressão para os Tipos 1, 2 e 3 após 7, 14 e 28 dias de cura.

A partir de uma análise do índice de vazios, Fig. 6 e do índice de absorção de água, Fig. 7, observou-se que a resistência à compressão é inversamente proporcional a estas duas propriedades, ou seja, quanto maiores forem os índices de vazios e de absorção de água, menor a resistência à compressão dos corpos-de-prova cerâmicos. Além disto, notou-se que a substituição de cal e areia por gesso representou uma queda de desempenho em todas as propriedades analisadas neste trabalho. Disto sugere-se trabalhar sem o uso de gesso ou reduzir sua carga de adição ao bloco cerâmico para não comprometer a resistência mecânica, principalmente.

De forma geral, a adição do pó de vidro nestes blocos não diminuiu a resistência à compressão, com isto a substituição dos componentes convencionais de argamassa (areia e cimento) por pó de vidro representa economia e uma atitude ecologicamente correta, como foi relatado no trabalho de Coutinho (2011). Além disto, evita-se descarte do pó de vidro proveniente da lapidação, o qual não pode aproveitado no processo de reciclagem do vidro.

\section{CONCLUSÃO}

Os blocos cerâmicos do Tipo 2 demonstraram características praticamente equivalentes a dos blocos cerâmicos convencionais Tipo 1 no que se refere às propriedades avaliadas neste trabalho.

Apenas os Tipos 1 e 2 tiveram resistência à compressão e índices de vazios e de absorção de água adequados, podendo os mesmos serem utilizadas para alvenarias de fechamento e estrutural.

Em geral, os blocos do Tipo 3 foram considerados inadequados por apresentar valores de resistência à compressão e índices de vazios e de absorção de água fora dos padrões exigidos para aplicação em alvenarias. Inferiu-se, assim, que a substituição de areia e cal por gesso na proporção aplicada no presente estudo não satisfaz o desempenho mecânico exigido. 
Os blocos do Tipo 2, com tempo de cura de 28 dias, apresentaram o maior valor de resistência à compressão. Disto, pôde-se inferir que a adição de pó de vidro à formulação convencional proporcionou um aumento de sua propriedade mecânica.

Através dos resultados obtidos da análise por FRX e DRX, pode-se concluir que o pó de vidro possui grande potencial para ser reaproveitado na construção de blocos cerâmicos por apresentar grande quantidade de óxido de silício; esta utilização representa economia e contribui para preservação ambiental, visto que este resíduo da lapidação de vidro poderia ser lançado na natureza por ser um subproduto que não reciclável.

\section{AGRADECIMENTOS}

Os autores gostariam de agradecer à CAPES, DVN Vidros LTDA, especialmente aos colaboradores mestres e doutorandos Patrícia Guilhermina da Silva Lêdo (análise granulométrica), Eugênio Teixeira de Carvalho Pinto (FRX), Jean Carlos Silva Andrade (moagem), Raimison Bezerra de Assis (DRX) e Francisco de Assis Braz (ensaio de compressão) e demais responsáveis pelos Laboratórios da UFRN: Laboratório de Materiais; de Máquinas Hidráulicas e Energias Renováveis; de Mecânica dos Fluidos; de Técnicas Mineral e de Materiais; Construção Civil e NUP-ER.

\section{REFERÊNCIAS BIBLIOGRÁFICAS}

1. ANGULO, S.C.; ZORDAN, S.E.; JOHN, V. M. Desenvolvimento sustentável e a reciclagem de resíduos na construção civil. IV Seminário Desenvolvimento Sustentável e a Reciclagem na construção civil - materiais reciclados e suas aplicações. CT206 - IBRACON. São Paulo - SP, 2001. Disponível em <http://www.reciclagem.pcc.usp.br/ftp/artigo\%20IV_CT206.pdf>. Acesso em: 07 de janeiro de 2013.

2. CEMPRE. Vidros - O mercado para reciclagem. Compromisso Empresarial para Reciclagem. Disponível em <http://www.cempre.org.br/ft_vidros.php>. Acesso em: janeiro de 2013.

3. COUTINHO, S. J. Betões eco-eficientes com resíduos. 1 Jornada de materiais na construção. pp. 171-214, 2011.

4. LIMA, N.M.O.; MORAIS, C.R.S.; LIMA, L. M. R. Lixo eletrônico: caracterização do vidro do tubo de raios catódicos de computadores para reciclagem. Revista Eletrônica de Materiais e Processos, v.6.1, pp. 59-62, 2011.

5. LUZ, A.P.I.; RIBEIRO, S. Uso de pó de vidro como fundente para produção de grês porcelanato. Revista Matéria, Rio de Janeiro, RJ, v. 13, n. 1, pp. 96 - 103, 2008.

6. RECICLAR PARA CONSTRUIR. [On-line]. Disponível em <http://www.reciclagem.pcc.usp.br/artigos.htm>. Acesso em: julho de 2013.

7. SANTOS, W.J. - Caracterização de vidros planos transparentes comerciais. Scientia Plena 5, $\mathrm{N}^{\circ} 2$, pp. 1-4, 2009.

8. SCARINCI, G.; BRUSATIN, G.; BARBIERI, L.; CORRADI, A.; LANCELLOTTI, I.; COLOMBO, P.; HREGLICH, S.; DALL'IGNA, R. Vitrification of industrial and natural wastes with production of glass fibers. Journal of the European Ceramic Society, v. 20, p. 2485-2490, 2000. 